\title{
MentorshiP: Linking InduSTRy Professionals With TOMORROW'S ENGINEERS
}

\author{
Kathryn Atamanchuk, Kristen Myles, and Morgann Becket \\ University of Manitoba, Engineers Geoscientists Manitoba (Committee for Increasing \\ the Participation of Women in Engineering) \\ kathryn.atamanchuk@umanitoba.ca
}

\begin{abstract}
In an effort to work towards the 30 by 30 goal established by Engineers Canada [1], the Committee for Increasing the Participation of Women in Engineering (CIPWIE), an operating committee of Engineers Geoscientists Manitoba, developed a Mentorship Program aimed at providing female engineering students with an opportunity to connect with female professional engineers to help provide a vision of what a career in engineering might look like. The CIPWIE Mentorship Program paired 35 female engineering students (between their second and fifth year of studies) with 33 female professional engineers through both a formal (eventdriven) and informal program carried out over the 2015/16 academic year. Surveys were used throughout the pilot program to participant feedback. Results of these surveys indicate that the program was a success with over $90 \%$ of participants indicating that they would reapply to the program in future years.
\end{abstract}

Keywords: 30 by 30 initiative, women in engineering, mentorship.

\section{INTRODUCTION}

The 30 by 30 goal is Engineers Canada's commitment to raising the percentage of newly licensed engineers that are women to $30 \%$ by the year 2030 [1]. This national goal has been endorsed by all 12 Canadian engineering regulatory bodies (including Engineers Geoscientists Manitoba), and many engineering schools (including the Faculty of Engineering at the University of Manitoba).

Currently, the percentage of female students enrolled at the University of Manitoba in undergraduate engineering programs sits at approximately 19\% [2], while the percentage of female professional engineers in Manitoba is approximately $8.5 \%$ [3]. This data shows that while there is still work to do to increase the recruitment of females into engineering education programs, there is a strong need to support women during their engineering education and as they progress through their careers in order to increase retention in the profession.
The Committee for Increasing the Participation of Women in Engineering (CIPWIE), an operating committee of Engineers Geoscientists Manitoba, is committed to assisting the association in achieving the 30 by 30 goal and to better understand and support the needs of Manitoba's female engineering cohort. Through committee meetings involving female engineers from a variety of industry sectors, CIPWIE identified mentorship as a potential solution help address the female engineering retention issue and move Manitoba towards achieving the 30 by 30 goal. Mentorship has long been known as an effective way to support skill development and learning, and can lead to increased career satisfaction and retention. Successful mentoring relationships can also extend well beyond knowledge transfer and develop into life-long relationships that are mutually beneficial to both the Mentor and the Student [4].

While mentorship programs do exist within Manitoba's engineering industry (for example the Association of Consulting Engineering Companies (ACEC) Manitoba mentorship program), there are no programs offered specifically by Engineers Geoscientists Manitoba or the University of Manitoba that are open to all engineering disciplines/industries. To this end, CIPWIE developed a student-driven Mentorship Program that pairs female engineering students with female professional engineers with the goal of providing students with an opportunity to see what a career in engineering could look like in the hopes that this would lead to increased retention in the profession over the long term.

This paper will provide details on the CIPWIE Mentorship Program, including results and feedback obtained, and recommendations for future program improvements.

\section{CIPWIE MENTORSHIP PROGRAM OVERVIEW}

The CIPWIE Mentorship Program, hereafter referred to as "the Program", aimed to pair approximately 35 engineering students at the University of Manitoba with 35 female professional engineers for a mentorship 
program that spanned the 2015/16 academic year. The Program provided four opportunities for formal mentorship and encouraged student-driven contact (informal mentoring) between events. The 'studentdriven' aspect of the Program is important as it puts the onus on the Student for making contact with their Mentor, which allows them to practice their communication and networking skills. The following subsections provide detail on the Program goals, participants, Mentor-Student matching process, and Program structure.

\subsection{Program Goals}

From the Student perspective, the primary goal of the CIPWIE Mentorship Program was to provide female engineering students with an opportunity to connect with a working female Professional Engineer, with the hope that this connection will lead to an increased retention of these students in the engineering profession once they have completed their schooling.

From the Student perspective, the goals of the Program were to provide students the opportunity to:

- gain insight into what it's like to be a working engineer;

- develop a picture of how they can see themselves in an engineering career;

- increase their understanding of specific engineering disciplines; and

- network with professional engineers.

From the Mentor perspective, the goals of the Program were to provide an opportunity to:

- share their passion for their chosen field of engineering and their career:

- gain experience in mentoring, coaching, and developing interpersonal relationships;

- be a role model;

- act as a medium for influencing the future of the profession; and

- develop a network of like-minded individuals.

\subsection{The Mentors}

Recruitment of Mentors for the Mentorship Program began in August 2015 through the Engineers Geoscientists Manitoba's weekly e-news email, via Friends of Engineering Manitoba, Inc. members, and through CIPWIE committee members' personal contacts. The Program required that applicants be female Professional Engineers registered with Engineers Geoscientists Manitoba, and have a willingness to embrace the role of mentor by making a diligent effort to make themselves available to their student. In their application forms, $75 \%$ of Mentor applicants indicated that they were made aware of the program through email announcements, and $29 \%$ indicated that they had enrolled based on discussions with friends and colleagues. At the end of the registration process, a total of 35 female Professional Engineers had applied to the Program. The areas of undergraduate study reported by the Mentors were: Mechanical (34.3\%), Civil $(22.9 \%)$, Other $(25.7 \%)$, Electrical $(8.6 \%)$, Computer $(8.6 \%)$, and Biosystems $(0.0 \%)$. Figure 1 illustrates the distribution of years of work experience of the Mentor applicants.

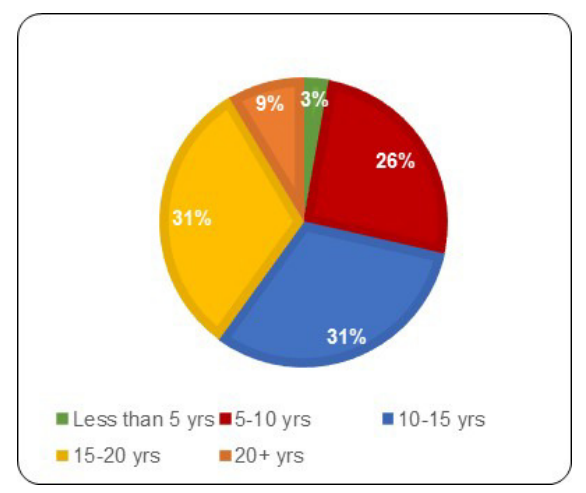

Fig. 1. Mentor respondents' years of experience

In an effort to gain a better understanding of the current engineering workplace climate, Mentor applicants were asked, "What do you attribute your success as a Professional Engineer to?" A summary of their responses is shown in Figure 2. While 'hard work' and 'perseverance' dominate the survey results, 'support systems' (which includes mentors) also play an important role in professional members' perceived success.

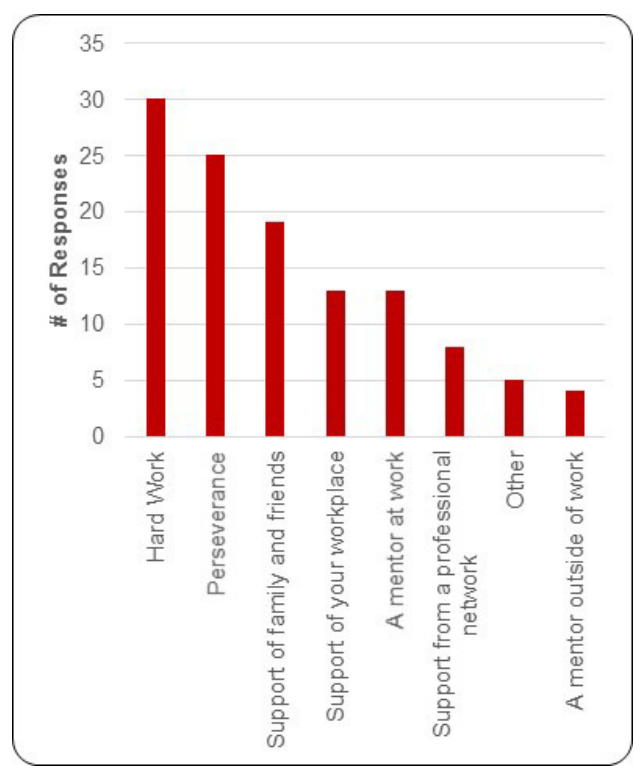

Fig. 2. What do you attribute your success as a Professional Engineer to? 


\subsection{The Students}

Recruitment of students into the Mentorship Program began in mid-September 2015, once the Fall academic term had begun. The Program required that Students be female undergraduate engineering students registered for the current academic year in the Faculty of Engineering at the University of Manitoba, entering at least their $2^{\text {nd }}$ year of engineering study. Students also needed to be willing to embrace the role of mentee by making a diligent effort to connect with their Mentor. Students were encouraged to apply for the Mentorship Program via an email invitation that was sent out to all female undergraduate engineering students in years $>2$ of their studies. Posters announcing the Program were displayed throughout the Engineering building. Word of mouth via the University of Manitoba Engineering Student Society (UMES) was also used to advertise the program. On their applications, $75 \%$ of Students indicated they were made aware of the program via the email invitations, and 30\% indicated that they were encouraged to apply to the program by a friend.

In total, 53 Student applications were received. Figure 3 shows that a relatively even distribution of students in years 2-5 of their undergraduate engineering studies applied to participate in the Program.

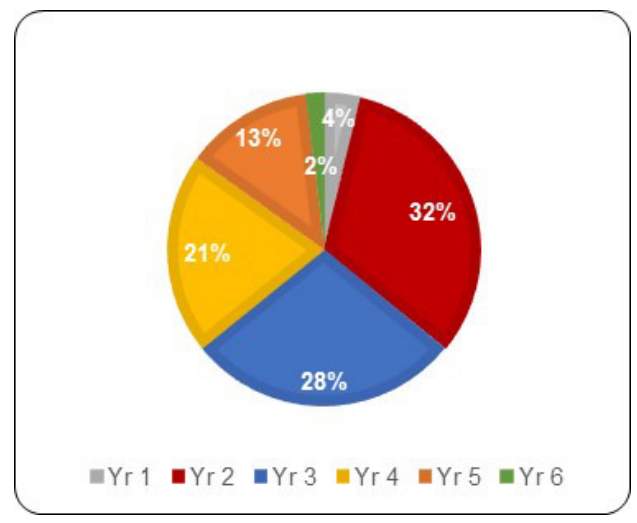

Fig. 3. Student respondents' year of study

The five major areas of technical interest reported by the Students were (note that multiple selections were allowed): Environmental (28.3\%), Mechanical (24.5\%), Structural (20.8\%), Planning (20.8\%), and Electrical (18.9\%). Approximately 15\% of Student applicants indicated they had previously participated in some form of a mentorship program, and $32 \%$ of applicants indicated that they had previous engineering work experience.

Figure 4 illustrates the various responses to this question "What career path do you envision for yourself at this point in time?" (note that multiple selections were allowed). 31 students indicated that they were "Unsure that's why I'm applying to the Mentorship Program".
This statistic is not surprising and reiterates the need for a mentorship program that helps provide a perspective of what 'real-world' engineering looks like.

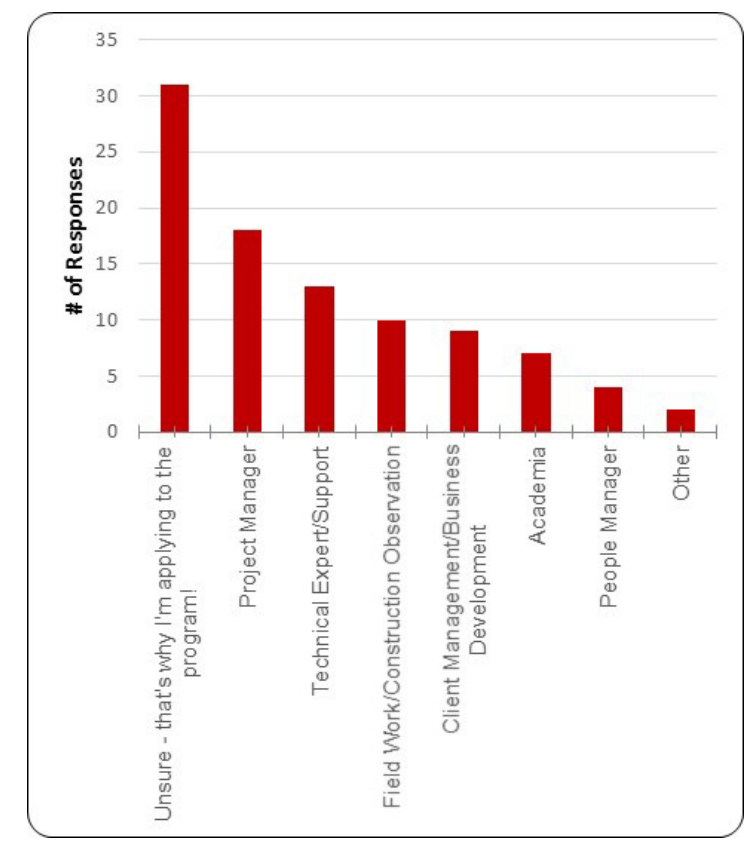

Fig. 4. What career path do you envision for yourself at this time?

\subsection{Mentorship Matching}

Mentorship matching can play a vital role in the success of a mentoring relationship [4]. When asked on the application form for the most important factor to be considered in a Mentor match, over 60\% of Student respondents indicated that common technical interest was a priority. To this end, Students and Mentors in the Program were matched, where possible, based on common technical area of interest (i.e. engineering discipline). Where this match was not possible, Students were matched with Mentors based on career path interests (for example, technical, construction, Project Management, business development), or by common extra-curricular activities. While this was a somewhat subjective matching process, the ultimate goal was to pair Students and Mentors in such a way as to maximize the chance of creating a mentorship match that 'clicked'. Since there were more Student applicants (53) than Mentor applicants (35), preference was given to students who had not previously participated in a mentorship program or had had minimal engineering related work experience.

During the matching process, two Mentors opted out of the Program due to work and personal conflicts. The matching process then resulted in 33 Mentors being matched with 35 students as two Mentors had indicated that they would be willing to take on two students each. 


\subsection{Mentorship Program Structure}

Effective mentorship programs should be well-planned and organized, with clear goals and expectations for all participants. To support this, the program coordinators developed the CIPWIE Mentorship Program Mentoring Policy Statement [5] that included details on the Program's background, goals, requirements, roles, expectations, and execution plan. In addition, A CIPWIE Mentorship Program Mentoring Agreement [6] was used to give each Program pair an opportunity to document their personal expectations and goals for the Program and develop an action plan to achieve said objectives.

Prior to the start of the Program, an orientation session was held for Mentors to provide them with an overview of the program and allow them an opportunity to ask questions and address concerns. A similar orientation session was held for Students just prior to the start of the first formal Mentorship event. In this session, the expectation that the Program was 'student-driven' was reiterated to the Students, along with some suggestions for how to initiate contact with their Mentors.

The first formal Mentorship Program event (Event \#1) was held on October 8, 2015 at the Hub on campus at the University of Manitoba. The event included the program orientation session for the Students and a Mentor/Student ice breaker activity. Students and Mentors were then given the opportunity to set mentorship expectations by completing the CIPWIE Mentorship Program Agreement [6]. Participants were given the opportunity to have their photo taken with their Mentorship pair to promote the \#ilooklikeanengineer campaign [7]. The event ended with networking to allow both Students and Mentors to get to know other participants.

The second formal Mentorship event (Event \#2) was held on November 26, 2015, again at the Hub on campus. This event included a "speed mentoring" activity where Students rotated between Mentors every three minutes to both gain valuable career advice as well as practice their networking skills. The evening also included a panel discussion with four leaders from the Manitoba engineering community. The panelists explored their personal challenges, their paths to success, the opportunities and challenges that exist for women in the engineering profession, and strategies that employers are implementing to help increase diversity within industry. Program participants were given an opportunity to ask questions and learn more about the panelists.

The third formal event (Event \#3) was held at the Manitoba Hydro Place in downtown Winnipeg. This award-winning, LEED platinum certified office building provided the backdrop for the event. The evening began with a presentation from Manitoba Hydro's Manager of Facilities and covered the engineering, architecture, and creativity behind the design of Manitoba Hydro Place.
The presentation was followed by a technical tour of the unique design features of the building and an opportunity for Program participants to network with one another.

The final formal Mentorship event (Event \#4) was held on March 31, 2016 at DeLuca's cooking school in Winnipeg. Students and Mentors enjoyed an evening of good food, cooking lessons, and networking. A photographer was on-site to capture candid photos of the event as well as professional 'headshots' of the Program participants.

\section{RESULTS AND DISCUSSION}

Since the Mentorship Program was a pilot initiative, it was important to gather feedback throughout the program, particularly regarding participant likes and dislikes and suggestions for improvement. This was accomplished through the use of post-event surveys that were administered via Google Forms Surveys sent to all participants via email. In addition to the event surveys, the program included a Mid-Term Program Assessment survey, administered in December 2015, and a PostProgram Assessment survey, administered in mid-April 2016, both via Google Forms.

The sub-sections below highlight some of the important feedback and statistics obtained via the Program surveys.

\subsection{Event Attendance}

With only four opportunities for formalized mentorship throughout the Program, attendance of both Students and Mentors at all events was important. Attendance requirements were made clear to all participants in the Mentoring Policy Statement [5] and orientation sessions and firm dates for all Program events were established at the outset of the program to ensure participants could commit to the dates. These strategies were very successful for the first two events where attendance at each exceeded 90\%. Attendance at Event \#3 was $73 \%$. The lower attendance at this event was attributed to the downtown location (which made it difficult for some Students to get to), and the date of the event, which coincided with midterm exams for some students and winter vacations for some Mentors. The attendance at Event \#4 was $80 \%$. The majority of participants that didn't attend were Mentors as it was found that the event fell during spring break in the Manitoba primary and secondary school system and many Mentors were busy with their families. It is clear from this data that close attention needs to be paid to the timing of events in the second half of the Program year to maximize attendance. 


\subsection{Event Satisfaction}

After each event, participants were surveyed on their satisfaction levels, including event length, format, venue, food and beverages, and overall rating. The Event \#1 survey had a $66 \%$ response rate with $90 \%$ of participants rating the overall event as "Very Good" or "Excellent". Event \#2 had an $84 \%$ survey response rate with $88 \%$ of participants rating the overall event as "Very Good" or "Excellent". Event \#3 and \#4 had survey response rates of $42 \%$ and $72 \%$ with overall event ratings of $100 \%$ and 95\%, respectively in the "Very Good" to "Excellent" categories. While there were some lessons learned that could lead to improvements in the flow and timing of the events, the survey results indicate that the events were well planned and executed.

\subsection{Mid-Term Survey Results Summary}

A mid-term program survey was issued via email to all in December 2015. A total of 19 Students (54.3\%) and 25 Mentors (75.8\%) responded to the survey. Mentors were asked "Approximately how many times have you met with or spoken to your student(s) in total, including at any formal mentorship program events?" the mean response was 4.5 times (with a low of 1 and a high of 10). At the four-month mid-point in the program, this equates to contact frequency between mentorship pairs of approximately once per month.

When questioned about the satisfaction with pairing "fit" on a scale of 1-5 (with 1 being poor compatibility or fit and 5 being ideal compatibility or fit), approximately $89 \%$ of Students and $80 \%$ of Mentors felt that their match was $4 / 5$ or better. The remaining survey respondents indicated a fit of no less than 3/5. These results indicate that the process used to pair Students and Mentors was effective.

\subsection{Post Program Survey Results Summary}

A post program survey was distributed to all Program participants via email in April 2016. A total of 21 Students (60\%) and 24 Mentors $(72.7 \%)$ responded to the survey. When Students were asked "Approximately how many times have you met with or spoken to your Mentor in total, including at any formal Mentorship Program events?" the average number of connections was 8.5 (with a low of 1 and a high of 25). It is clear from the data that some pairs connected more than others, however, over the eight months of the Program, the data suggests that most pairs met at least once per month. This is in line with the expectations set out by the Program coordinators.

To better understand how Students and Mentors connected with one another, Mentors were asked "How have you interacted with your Student(s) to date?" A summary of the various methods for mentorship interaction are shown in Figure 5 (note that multiple selections were allowed). It is not surprising that email was the most frequent method of communication due to its ease of use, but it is important to note that the next four most frequent methods of interaction all involve face-toface activities. Face-to-face interactions allow for the use of non-verbal communication which can help strengthen the relationship, while virtual mentoring, via means such as email, allows for participants to better manage their time constraints [8]. Using a combination of face-to-face and virtual mentoring strategies allows participants to take advantage of the benefits of both.

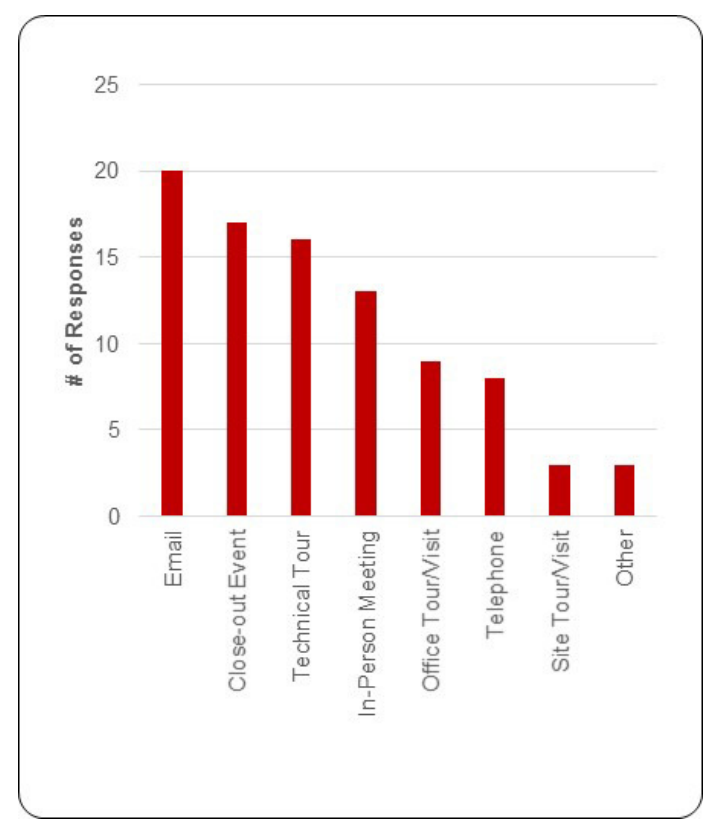

Fig. 5. How have you interacted with your Student(s) to date?

Both Students and Mentors were asked "Would you reapply for the Program in future years?". $90.5 \%$ of Students and $100 \%$ of Mentors indicated that they would interested in re-applying (for Mentors, 91.7\% indicated 'yes', while $8.3 \%$ indicated 'maybe'). These numbers indicate a high satisfaction level with the program.

Participants were also asked to provide recommendations to improve the Program. A common theme from both Mentors and Students was a request for more ideas and suggestions for informal mentorship activities that could be carried out between formal events. Several Mentors stated that they would like to see more time for networking at each formal event as they appreciate the opportunity to network with their peers in addition to the students. 


\section{NEXT STEPS}

Due to the success of the pilot Mentorship Program, CIPWIE plans to run the program again in the 2016/17 academic year. The program will be extended to include a tri-mentorship model where a professional engineer is matched with an Engineer-in-Training and an engineering student. This model will allow engineering students to connect with working engineers who are new to the profession as well as those with more experience. It will provide Engineers-in-Training and professional members with an opportunity to develop and/or hone their mentorship skills and it will further expand the professional network of women in the Manitoba engineering profession. When Mentors were asked "Would you be willing to be paired with and EIT and a Student in future years?" $71 \%$ said yes, while $25 \%$ indicated that they would like more information about a tri-mentorship model. This indicates high support for the program expansion.

Surveys and participant feedback will continue to be an important part of the Program going forward and it is recommended that someone familiar with qualitative research methods be brought in to consult on Program survey development to ensure that the most pertinent data is captured for analysis and action.

Finally, the program coordinators will develop a more robust Mentorship Guide to provide both Students and Mentors with additional suggestions for informal mentorship activities, ways to connect, and discussion topics to further support the mentoring relationships.

\section{CONCLUSIONS}

Encouraging women to remain in the engineering profession begins when they are still in school. By pairing female undergraduate engineering students with female Professional Engineers, the students are given an opportunity to better visualize and understand what a career in the engineering profession might look like and how they might fit in. However, it is recognized that mentorship is not a one-time activity. A successful mentorship program can be viewed as one that encourages participants to seek out further opportunities to build mentorship relationships. From the perspective of the Program coordinators, success in the CIPWIE Mentorship Program is indicated by the fact that over $90 \%$ of both Students and Mentors said they would reapply to the program in future years, thus suggesting a continuation of their interest in not only mentorship, but in the engineering profession itself.

\section{Acknowledgements}

The CIPWIE Mentorship Program was made possible through the generous funding and support provided by Engineers Geoscientists Manitoba, the Faculty of Engineering at the University of Manitoba, Friends of Engineering Manitoba, Inc., and Dr. Annemieke Farenhorst, the Prairie NSERC Chair for Women in Science and Engineering. The authors would also like to acknowledge and thank the many female engineers and students who so generously volunteered their time to participate in this Program. They did so with enthusiasm and commitment, contributing valuable suggestions and feedback to help improve the program.

\section{References}

[1] 30 by 30. (2016, May 7). Retrieved from https://www.engineerscanada.ca/30-by-30

[2] Jonathan Beddoes, University of Manitoba. Diversity of Enrolment. Unpublished manuscript, 2016.

[3] Michelle Wadelius. " 30 by 30 and Women in Engineering in Manitoba, The Keystone Professional, pp. 36-37, Autumn 2015. Available from: http://www.apegm.mb.ca/pdf/Keystone/15Autumn.pdf

[4] Michael Garringer, Patti MacRae, and Susan Weinberger. Going the Distance: A Guide to Building Lasting Relationships in Mentoring Programs. Folsum, CA: Dennis Wakeland, 2005, 51 pp. \{ISBN: 0-89354073-0\}

[5] Kathryn Atamanchuk, Morgann Becket, and Kristen Myles, CIPWIE Mentorship Program: Mentoring Policy Statement. Unpublished manuscript, 2015.

[6] Kathryn Atamanchuk, Morgann Becket, and Kristen Myles, CIPWIE Mentorship Program: Mentoring Agreement. Unpublished manuscript, 2015.

[7] Jessica Guynn, “\#ILookLikeAnEngineer challenges stereotypes," USA Today. Available as of August 4, 2015 from http://www.usatoday.com/story/tech/2015/08/03/isiswenger-tech-sexism-stereotypes-

ilooklikeanenginer/31088413/

[8] Laura Jerpi. Face-to-Face vs. Virtual Mentoring. (2016, May 7). Retrieved from http://work.chron.com/facetoface-vs-virtual-mentoring3464.html 